\title{
Modeling of dendrite growth in undercooled solution sodium acetate trihydrate
}

\author{
Chanchal Kumar ${ }^{1}$, Aniket D. Monde ${ }^{2}$, Anirban Bhattacharya ${ }^{3}$, and Prodyut R. Chakraborty, ${ }^{2, *}$ \\ ${ }^{1}$ Defence Laboratory, DRDO Jodhpur, 342011, India \\ ${ }^{2}$ Department of Mechanical Engineering, IIT Jodhpur, 342037, India \\ ${ }^{3}$ Department of Mechanical Engineering, IIT Bhubaneswar, 752050, India
}

\begin{abstract}
The sodium acetate trihydrate is commonly used as energy storage phase change material in heating pads for body or hand warmer in cold climates. The undercooled melt of sodium acetate trihydrate kept at room temperature results in an exothermic reaction when solidification seed is nucleated. In present work, modeling of denritic growth in an undercooled solution of sodium acetate trihydrate has been carried out. The enthalpy method has been used to compute solid-liquid interface growing in undercooled melt. The interface temperature, concentration and grain growth have been modeled considering curvature effect and solutal undercooling. A 2-D computational grid of square control volumes has been used and discreatized governing equations were solved explicitly. The crystal anisotropy was imposed explicitly. The results are validated using experimental data.
\end{abstract}

\section{Introduction}

Under-cooling is a process of cooling a liquid below its solidification temperature without it becoming a solid. It is possible to under-cool a liquid below its solidification temperature if due care is taken. Several methods have been developed to track the evolution of the solid-liquid interface of a dendrite growing in undercooled melt. These methods can broadly classify into two categories, i.e., front tracking methods and order parameter methods.

The front tracking can use deforming grids that evolve with the solid-liquid interface. Order parameter characterizes the position of the interface by an order parameter $0 \leq \Phi \leq 1$. Three popular order parameter methods are enthalpy [1, 2], level-set [3], and phasefield. In present work enthalpy as an order parameter is used for tracking the evolution of the solid-liquid interface of a crystal growing in an under-cooled [1, 2]. Zhiwei Ma et.al.[4] have conducted a study on the solidification process of sodium acetate tri-hydrate for solar energy storage application.

In the present work, enthalpy method has been used to track solidification in the domain. The location of the solid-liquid interface is specified at any time instance using the liquid fraction $\mathrm{f}_{\mathrm{l}}$. The value of $0<\mathrm{f}_{-} \mathrm{l}<1$ describes the vicinity of the interface. The energy \& solute concentration equations are required to be solved, together with the temperature-concentration relation as per the phase diagram, to obtain the liquid fraction field. The nodes can be divided into three types i.e. solid nodes $\left(f_{l}=0\right)$, liquid nodes $\left(f_{l}=1\right)$ and two-phase nodes $\left(0<\mathrm{f}_{\mathrm{l}}<1\right)$.
Present numerical analysis is diffusion dominant and thus follows the same non-dimensional governing equations as reported in [1, 2]. A 2-D insulated representative square domain is considered, as shown in Fig. 1., initially filled with undercooled SAT at temperature $250^{\circ} \mathrm{C}$ and concentration $\left(C_{0}=0.6\right)$. Due to four fold symmetry, analysis is performed by placing the seed at the bottom left corner (positive quadrant).

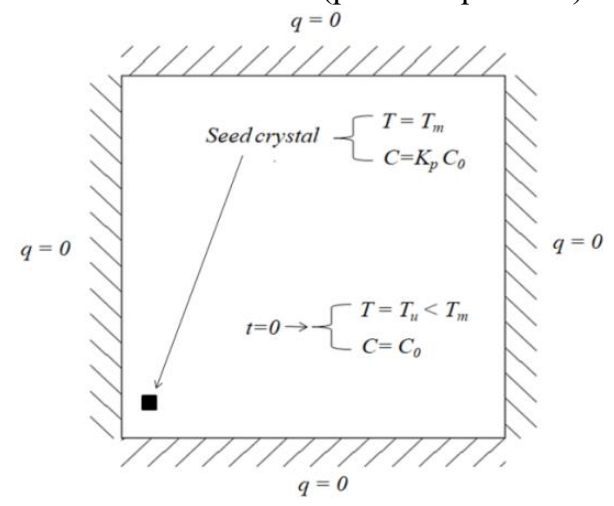

Fig. 1. Computational domain showing initial \& boundary conditions

\section{Analysis and Modelling}

For the present numerical study, the non-dimensional form of continuity, momentum, energy, and solute transport equations is used. The parameters used for the calculation have been scaled using capillary length scale $\left(\mathrm{d}_{0}=10^{-10} \mathrm{~m}\right)$. Following assumptions were made for modeling of solidification are (a)The liquidus line in the phase diagram is linear., (b) The effect of buoyancy and shrinkage is neglected., (c) The thermo-physical 
properties of SAT are independent of temperature., and (d) The effect of kinetic and pressure under-cooling are ignored.

The non-dimensional governing equations used in the computation are as follows $[1,2]$ :

Energy

Solute transport

$$
\frac{\partial}{\partial \mathrm{t}^{*}}\left(\mathrm{H}^{*}\right)=\nabla^{*} \cdot\left(\mathrm{K}^{*} \nabla^{*} \mathrm{~T}^{*}\right)
$$

Interface temperature

$$
\frac{\partial}{\partial \mathrm{t}^{*}}\left(\mathrm{C}^{*}\right)=\nabla^{*} \cdot\left(\mathrm{D}^{*} \nabla^{*} \mathrm{~T}\right)
$$

The fully explicit schemes of eqn. (1) and (2) are

$$
\begin{aligned}
\mathrm{H}_{\mathrm{i}, \mathrm{j}}^{\text {new }}=\mathrm{H}_{\mathrm{i}, \mathrm{j}}+\frac{\Delta t}{\Delta^{2}} & {\left[\mathrm{~K}_{\mathrm{w}}\left(\mathrm{T}_{\mathrm{i}, \mathrm{j}-1}-\mathrm{T}_{\mathrm{i}, \mathrm{j}}\right)\right.} \\
& +\mathrm{K}_{\mathrm{s}}\left(\mathrm{T}_{\mathrm{i}-1, \mathrm{j}}-\mathrm{T}_{\mathrm{i}, \mathrm{j}}\right) \\
& +\mathrm{K}_{\mathrm{n}}\left(\mathrm{T}_{\mathrm{i}+1, \mathrm{j}}-\mathrm{T}_{\mathrm{i}, \mathrm{j}}\right) \\
& \left.+\mathrm{K}_{\mathrm{e}}\left(\mathrm{T}_{\mathrm{i}, \mathrm{j}+1}-\mathrm{T}_{\mathrm{i}, \mathrm{j}}\right)\right] \\
\mathrm{C}_{\mathrm{i}, \mathrm{j}}^{\text {new }}=\mathrm{C}_{\mathrm{i}, \mathrm{j}}+\frac{\Delta t}{\Delta^{2}} & {\left[\mathrm{D}_{\mathrm{w}}\left(\mathrm{V}_{\mathrm{i}, \mathrm{j}-1}-\mathrm{V}_{\mathrm{i}, \mathrm{j}}\right)+\mathrm{D}_{\mathrm{s}}\left(\mathrm{V}_{\mathrm{i}-1, \mathrm{j}}-\mathrm{V}_{\mathrm{i}, \mathrm{j}}\right)\right.} \\
& +\mathrm{D}_{\mathrm{n}}\left(\mathrm{V}_{\mathrm{i}+1, \mathrm{j}}-\mathrm{V}_{\mathrm{i}, \mathrm{j}}\right) \\
& \left.+\mathrm{D}_{\mathrm{e}}\left(\mathrm{V}_{\mathrm{i}, \mathrm{j}+1}-\mathrm{V}_{\mathrm{i}, \mathrm{j}}\right)\right]
\end{aligned}
$$

Here, $\Delta \mathrm{t}$ is time step and $\Delta$ is space step. The subscript $\mathrm{w}, \mathrm{s}, \mathrm{n}$, and e denotes face value of control volume i.e. west, south, north, and east respectively.

The phase diagram of SAT [4] is given in Fig. 2. The liquidus line is shown in the figure is a higher order polynomial. However, due to complexities involved in computations, it is assumed being straight as marked with modified liquidus line. The slope of the modified liquidus line $(\mathrm{m})$ is 223 . The thermophysical properties of SAT used for the analysis are given in Table 1 .

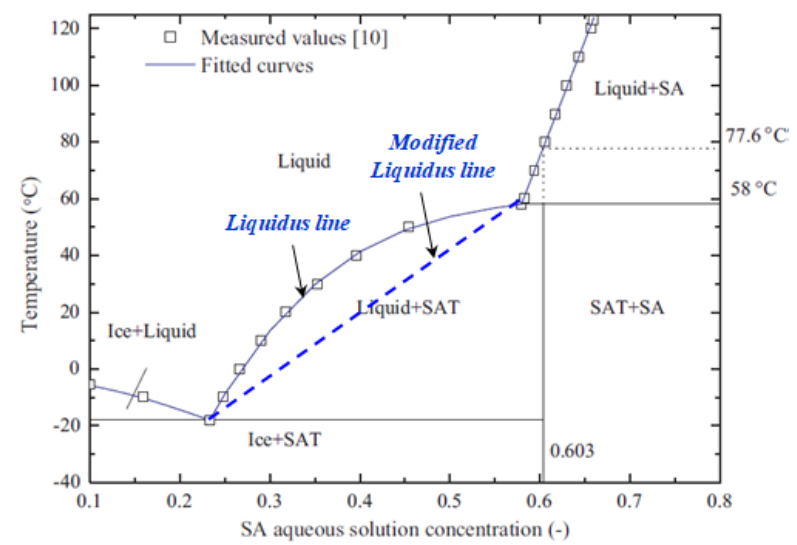

Fig. 2. Phase diagram of sodium acetate tri-hydrate aqueous solution

Table 1. Properties of SAT used during numerical investigation [3]

\begin{tabular}{ll}
\hline$k_{l}=0.7 \mathrm{~W} / \mathrm{mK}$ & $k_{s}=0.8 \mathrm{~W} / \mathrm{mK}$ \\
$C_{p l}=3300 \mathrm{~J} / \mathrm{kg} \mathrm{K}$ & $C_{p s}=2800 \mathrm{~J} / \mathrm{kg} \mathrm{K}$ \\
$\rho=1459 \mathrm{~kg} / \mathrm{m}^{3}$ & $\gamma=0.0556 \mathrm{~N} / \mathrm{m}$ \\
$h_{s l}=250000 \mathrm{~J} / \mathrm{kg}$ & $T_{m}=58^{0} \mathrm{C}$ \\
\hline
\end{tabular}

\section{Results and Discussion}

A coupled explicit-implicit scheme is used for solving the equations. The energy \& species equations are solved using a finite difference scheme given in [5]. Similarly, the continuity and momentum equations are solved using the implicit pressure-based finite volume approach according to the SIMPLER algorithm [6].A code in FORTRAN has been written to solve these equations.

The initial configuration taken as $x=y=8000$, time step $=100, \quad C_{0}=0.6, T_{0}=25^{\circ} \mathrm{C} . \quad$ At a preliminary stage, results of non-dimensional temperature and grain growth distribution at the end of the solidification are presented in Fig. 3 and Fig. 4 respectively. It can be observed that temperature is maximum near the seed location and gradually decreases away from it. This can also be also co-related with the grain growth field. At $t=0 s$ the solution is in undercooled state and the computation domain is in liquid state. As, the solid seed is nucleated, the grain starts growing. The grain growth at different time steps is shown in Fig. 4.

(a) Temperature contour

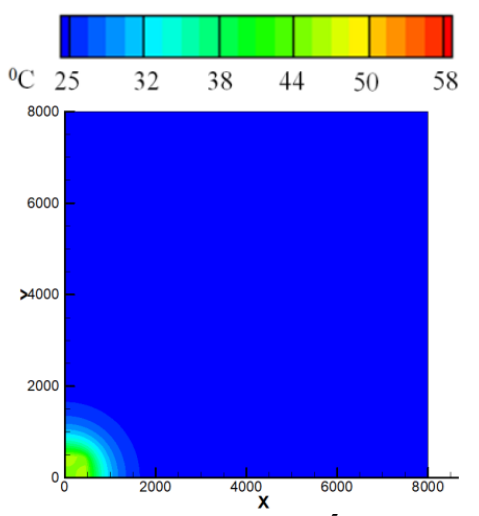

(a) At Time step : $5 \times 10^{5}\left(1.375 \times 10^{-7} \mathrm{~s}\right)$

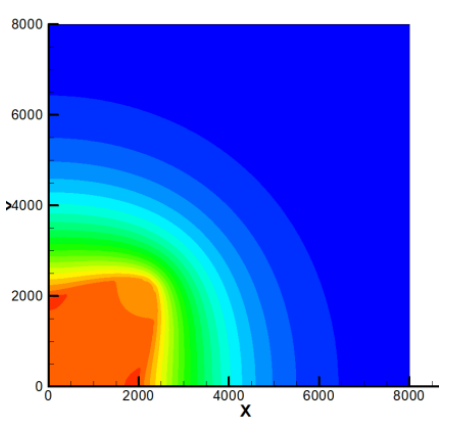

(b) At Time step: $50 \times 10^{5}\left(3.439 \times 10^{-7} \mathrm{~s}\right)$

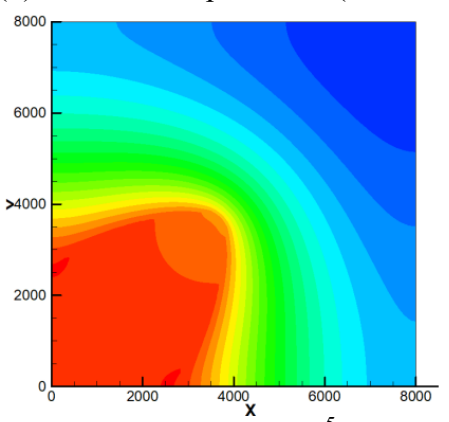

(c) At Time step: $100 \times 10^{5}\left(6.878 \times 10^{-7} \mathrm{~s}\right)$

Fig. 3. Stated temperature at different time steps of solidification 
(b) Grain growth

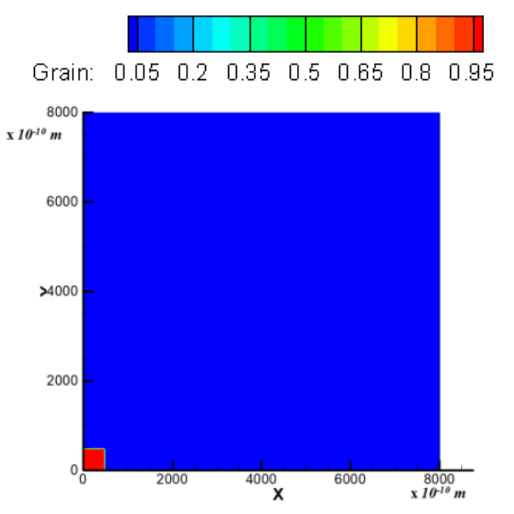

(a) At Time step : $5 \times 105(1.375 \times 10-7 \mathrm{~s})$

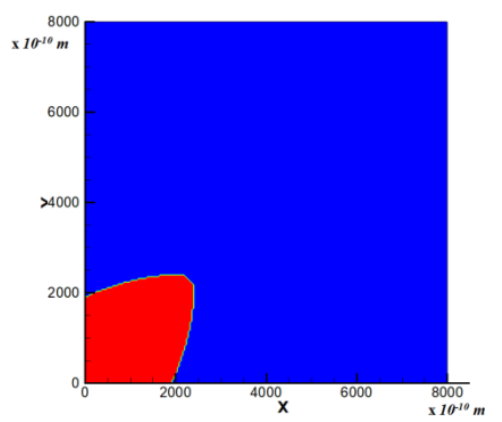

(b) At Time step: $50 \times 105(3.439 \times 10-7 \mathrm{~s})$

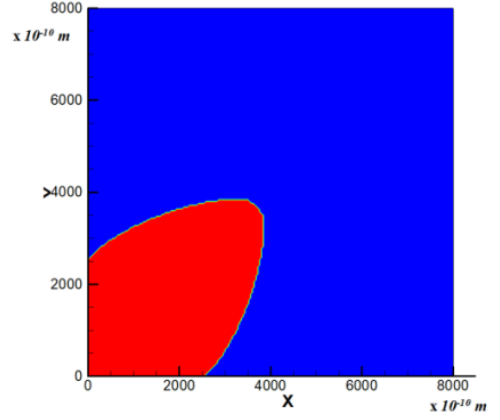

(c) At Time step: $100 \times 105(6.878 \times 10-7 \mathrm{~s})$

Fig. 4. Stated temperature at different time steps of solidification

\section{Conclusions}

The modeling of dendrite growth in undercooled solution of sodium acetate trihydrate has been carried out using enthalpy method. Coupled explicit-implicit scheme is used for solving the equations. The energy \& species equations are solved using a finite difference scheme. A $0.8 \times 0.8$ micron square computation domain has been used with uniform grid of $200 \times 200$. The seed is placed bottom left corner of computation domain. It is observed that the seed nucleate solidification. The temperature and grain growth takes place with time. The results show that the temperature of solidified grain reaches to its solidification temperature.

\section{References}

1. V.R. Voller, Int. J. Heat Mass Transf., 2008, vol. 51, pp. 823-834.

2. A. Bhattacharya, P. Dutta, Int. J. Numer. Methods Heat Fluid Flow, 2013, vol. 23, pp. 1121-1135.

3. Y.T. Kim, N. Goldenfeld, J. Dantzig, Phys. Review E, 2000, vol. 62, pp. 2471.

4. Z. Ma, H. Bao, A.P. Roskilly, Solar Ener. Mater. Solar Cells, 2017, vol. 172, pp. 99-107.

5. S. Karagadde, A. Bhattacharya, G. Tomar, P. Dutta, J. Compu. Phys., 2012, vol. 231, pp. 39874000.

6. S. Patankar, Numer. Heat Transf. Fluid Flow. 1980, CRC press. 